\title{
The use of epistemic distancing to create a safe space to sensemake in introductory physics tutorials
}

\author{
Luke D. Conlin ${ }^{1}$ \\ ${ }^{I}$ Salem State University, Department of Chemistry and Physics, \\ 352 Lafayette St., Salem, MA, 01908
}

\begin{abstract}
In active engagement physics classrooms, students get opportunities to make sense of physics together through discussion. They do not always take up these opportunities, in part because of the risk of sharing their ideas and having them rejected by their classmates or the instructors. In this case study, I analyze videotaped discourse of a tutorial group's early discussions to investigate how students manage these risks in creating a safe space to sensemake. I find that the students rely on a discursive resource - epistemic distancing - to share their ideas while protecting themselves affectively if others disagree. Epistemic distancing includes hedging, joking, deferring, and other discourse moves used to soften one's stance in conversation. I use video analysis to illustrate the effects of these moves on one tutorial group's initial sensemaking discussions. I then discuss implications for instructors wishing to encourage sensemaking discussions in their physics classrooms.
\end{abstract}

\section{INTRODUCTION}

The Active engagement classrooms give students opportunities to learn physics by discussing their ideas with their classmates. For instance, in the Tutorials in Physics Sensemaking [1] students work together in groups of four to make sense of conceptual and epistemological issues in physics through worksheet-guided discussions. Discussing their ideas involves risk - including the risk of sharing ones' ideas and possibly having them rejected by their peers or by the instructor. If students are to engage in sensemaking discussions, they must find ways to manage these risks.

To understand how tutorial groups first created a safe space to sensemake within their discussions, I analyzed three student groups' first discussions of the semester. Here I present a case study of one of the groups to illustrate the construct of epistemic distancing and its critical role in the groups' constructing a safe space to discuss their physics ideas. I find that the students and instructors use hedging, joking, quoting and other discourse moves I classify as epistemic distancing to soften their stance and make room for sensemaking.

This paper first characterizes discourse moves that involve epistemic distancing. Then it presents a case study of two early discussions of one group to illustrate how students' use of epistemic distancing - and instructors' encouragement of that use - makes space for the group to collaboratively make sense of physics.

\section{EPISTEMIC DISTANCING}

Discourse analysts have shown how people soften their stance in conversation to manage conflicts [2]. Hedging, by using phrases such as "I think," or "I guess" is one way of softening one's stance, as is quoting another person or deferring to others $[2,3]$. Students use these distancing moves to manage conflict by expressing a contrary position without escalating the conflict, for example on collaborative writing tasks [2].

In active engagement classrooms in which students discuss their ideas, conflict is even more likely to occur, in part because students are likely to have different ideas about the same phenomenon. But little research has explored how students manage conflict in face-to-face interactions in science classrooms. In such environments, words are not the only way to downgrade epistemic stance. Claims can be softened by phrasing them as a question, or by simply using a rising intonation that suggests uncertainty [4]. Epistemic stance can be downgraded based on body positioning as well [5].

Any discourse move by which speakers soften their stance, including hedging, joking, and deferring, I characterize as epistemic distancing. Epistemic distancing is "epistemic" in that it concerns the speaker's commitment to the truth of what they are saying. It is "distancing" in that it creates distance between the speaker and what they are saying [6]. This distance protects the speaker against embarrassment in the event that the idea gets evaluated negatively, thereby reducing ego threat.

In small group discussions, students can distance themselves from their ideas about physics or from their ideas about how to go about learning physics together. In constructing a safe space to make sense of physics together, students must establish a norm of contributing their own ideas, and a norm of collaboratively evaluating those ideas. This mirrors the essential tension of science between generating hypotheses and critically evaluating those hypotheses [7, 8]. Epistemic distancing can help students evaluate the ideas, rather than the person coming up with them. This protects students from being embarrassed by any negative evaluation of their ideas, so that they are not discouraged from contributing more ideas to the discussion.

This is not to say that more epistemic distancing is necessarily better. Students who distance themselves too much 
from their ideas about physics or how to learn physics can come across as so dismissive of the activity that they discourage further contributions.

I find that the tutorial students use epistemic distancing in ways that are consequential for making a safe space to sensemake. I will detail how one group first constructed a safe space to make sense of physics, illustrating the critical role that epistemic distancing played in this process.

\section{METHODS}

\section{Instructional context}

The video data analyzed come from the tutorial section of an algebra-based introductory physics course. The students are primarily life sciences majors in their junior year. In tutorial, students meet weekly for a 50-minute worksheetguided inquiry into select topics in physics. The worksheets focus on developing conceptual understandings in physics, as well as epistemological understandings about how to approach learning physics.

The students work together in small groups. Although seated is not assigned, the groups tend to remain intact through the semester. Two groups in each session were videotaped with a static camera and audio recorded using a microphone embedded in the table.

\section{Video analysis}

This paper presents a case study in which video records of students' discourse in tutorials were analyzed [8] to gain insight on the communicative processes by which groups enter into collaborative sensemaking discussions. The full analysis focuses on three tutorial groups that provided a range of levels of engagement in the tutorials [10].

Using the methods described in Scherr \& Hammer [9], I identified all of the times each group was engaged in discussion throughout the semester. To analyze how groups were able to initially construct a safe space to sensemake, I selected each group's very first discussion, as well as their first discussions containing significant evidence of mechanistic reasoning [11]. I then conducted a close discourse analysis of the moments surrounding the transitions into these sensemaking conversations, finding that epistemic distancing moves (hedging, joking) played a key role.

I focus the analysis here on just one of the groups to provide insight into the discursive processes by which they constructed a safe space to sensemake. I selected this group because their sudden shift in engagement, from dismissal of the tutorial activity to collaboratively sensemaking, highlights the critical nature of epistemic distancing for introducing ideas and evaluating them together.

\section{DATA \& ANALYSIS}

I focus the analysis on two early discussions of one group, consisting of four students (pseudonyms: Alan, Brandi, Chrissie, and Daria). Both discussions take place during the first tutorial session of the semester, which explores conceptual and epistemological issues related to learning about motion graphs. In this tutorial, the students use a motion detector to make real-time graphs of their motion, which is displayed on a computer screen.

\section{A. Episode 1 - "Whatever. Next!"}

The very first question of the first tutorial asks students to consider the benefits of discussing their mistakes in physics, and to write down their thoughts. It then asks them to discuss their answers, making a note of any differences.

The students had been hunched over their respective worksheets, reading and writing. One by one, the students look up at each other, and begin to laugh. Then they very briefly discuss the first question:

\begin{tabular}{|c|c|}
\hline \multicolumn{2}{|c|}{ CHRISSIE: ((laughs)) } \\
\hline DARIA: & $\begin{array}{l}\text { So...okay...we talked about how you can learn } \\
\text { from your mistakes pretty much yeah. }\end{array}$ \\
\hline ALAN: & $\begin{array}{l}\text { Yeah I think everyone said 'learning from your } \\
\text { mistakes,' right? }\end{array}$ \\
\hline DARIA: & Yeah. \\
\hline BRANDI: & Right. \\
\hline \multicolumn{2}{|c|}{ CHRISSIE: ((laughs)) } \\
\hline DARIA: & Pretty much okay. \\
\hline ALAN: & Whatever. Next! \\
\hline
\end{tabular}

Chrissie's laughter could imply a lack of seriousness, but it seems more likely to be a response to the discomfort of beginning a conversation. Daria was the first to discuss her answer, and she distances herself from her own response in several ways. First, she phrased her answer as "we" instead of "I", reducing her personal responsibility. She also did not share exactly what she thought or wrote, choosing to summarize instead and qualifying with a hedge ("pretty much"). Alan also did not share exactly what he thought, instead saying what he thought everyone wrote. While this may build some comradery with the group, it also reduces his personal responsibility for sharing ideas, and gives the others an "escape hatch" [12] from further discussion. This is a case of "too much" epistemic distancing, since they distance themselves in a way that they have the effect of the group avoiding discussing their ideas.

The group continues in this dismissive approach to the tutorial questions until later on in the first tutorial, when a teaching assistant (TA) overhears a good question and uses it as an opportunity to get them discussing their ideas. 


\section{B. Episode 2 - "Just getting started up"}

Later in the same tutorial session, the group is working on a question about motion graphs. The worksheet asked them to make a prediction of a distance vs. time graph of a person walking slowly and steadily away from a motion detector. They had all predicted that it would make a straight line with positive slope. Then the worksheet asked for a group member to walk in front of the detector to make the graph.

As the walker, Alan starts half a meter away from the detector, holding a book up as a target, and then walks slowly back. As he is returning to the table, he notices two unexpected "jumps" in the graph:
ALAN: Wh- what are those two jumps?
DARIA: ((Laughing)) Heh- I don't know.
ALAN: Whatever. ((Sits down))
CHRISSIE: Okay, ((reading out loud and trailing off)) "Sketch the result" TA: $\quad$ So wait a second, that's a good question.
What are those two jumps?

Alan asked the group what made the two apparent "jumps" in the graph, but then the group once again takes a dismissive approach. Daria distances herself from knowing by laughing and saying, "I don't know." Alan dismisses the question by saying "Whatever" as he sits down and starts to move on. Chrissie starts to read the next tutorial question, deferring to the worksheet. All of these moves increase the epistemic distancing so much that there is no space to have a discussion.

Having overheard Alan's question, the TA then uses it to try to get them discussing their ideas. He points it out as a good question and poses it again to the group, "What are those two jumps?" Still, their only response is "I don't know". While the group had been using too much distancing to encourage their sharing of ideas, the TA's question seems to use too little.

The TA then modifies the question from "what happened there" to "what do you think happened there?". He also asks for "any idea". Both of these moves encourage the students to use epistemic distancing in order to share their ideas, rather than avoid sharing altogether. By asking what they "think" and soliciting "any idea", the TA opens up space for someone to offer an idea even if they do not know for sure. As he asks this question, he also kneels down to eye level with the students, reducing his authoritative stance, which may further encourage discussion [Fig 1].

At this point, the students tentatively offer ideas about what may have happened:

DARIA: Something wrong must have happened.

ALAN: I dunno, maybe...this [detector] was weird?
So, what do you think happened there, do you have any idea?

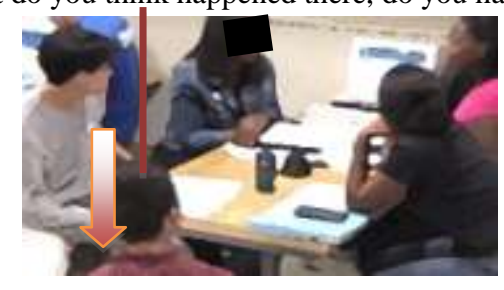

FIG 1. The TA kneels down as he rephrases the question with more epistemic distancing.

DARIA: ((laughs))

TA: Maybe it was weird. What do you mean by'Weird' could mean a lot of things.

DARIA: Maybe it's just getting started up or something.

TA: It was getting started up, so like if we did it again, like now it's warmed up almost

DARIA: Maybe...

ALAN: Maybe...

CHRISSIE: I think we should do a second trial, to see

The students use epistemic distancing when tentatively introducing their ideas. Daria starts off with a general idea that "something wrong" happened. Alan suggests that maybe the detector was "weird". It seems that Alan may be halfjoking (Daria laughs), but the TA takes his idea seriously by echoing it back to him and asking him to be more specific. Daria offers an idea, "Maybe it's just getting started up or something" which she hedges by leading with "maybe" and ending with "or something". The TA also takes her idea seriously by echoing it once again, and pushes it further to infer a prediction: "so like if we did it again..." Chrissie then suggests they do another trial.

At this time, the TA tells the group that "this is the sort of thing we want you to investigate...this MOSTLY fits with your prediction, but there's some discrepancies..." and suggests they try it again. After the TA leaves, the group does another trial, with Alan walking slowly away. The group watches the screen carefully and as a straight line is drawn, this time with no "jumps". Daria exclaims, "THERE you goooo!" and Chrissie adds, "Ahhhh, okay!"

The group laughs and starts to move on to fill in the worksheet, but Chrissie keeps the discussion going by offering another idea of what might have happened:

CHRISSIE: So maybe you weren't walkin' at a steady pace at one point

ALAN: Probably, I probably moved the book or something like that

DARIA: Did you? Yeah maybe.

ALAN: Yeah. 
DARIA: Wait did you do something different the first time?

ALAN: No.

DARIA: Like, while you were walking back?

ALAN: I was- I probly...I donno either=

BRANDI: Sometimes you do things subconsciously

ALAN: =moved the book down or, you know, yeah.

Even though the TA is no longer there, the group does not continue their dismissive approach to tutorial. They conduct another trial, and are happy when it yields better results. But they are not satisfied with the better graph; they continue his push to seek to understand what may have caused the discrepancy. In explaining the mysterious jumps, they are considering multiple mechanisms, including whether Alan had walked at a steady pace, or if he had inadvertently lowered the book he was holding as a target for the detector.

Despite their initially dismissive approach to the tutorial, the group is able to use epistemic distancing to share and evaluate their own ideas to make sense of the mechanism. Although they did this in direct response to the TA's encouragement, they continue to discuss and evaluate their ideas after the TA leaves. In fact, they continue to have frequent discussions in which they collaboratively sensemaking throughout the semester.

\section{DISCUSSION}

The purpose of this paper is not to make generalizations to all tutorial groups, but rather to (1) illustrate the construct of epistemic distancing and (2) how it can play a role in a group first constructing a space to sensemake. Future work [13] will explore the dynamics of epistemic distancing across multiple tutorial groups' early tutorial discussions.

Even given the constraints of the current study, there are several implications worth drawing out. An implication for research is the demonstration of how conceptual reasoning can be coupled with epistemology as well as with affect. These students noticed a discrepancy in the graph they did not understand, but were uncomfortable sharing their uncertain ideas until a TA encouraged them to do so. This highlights an implication for instruction, namely, that small

[1] http://spu.edu/depts/physics/tcp/tadevelopment.asp

[2] E. Kärkkäinen, Text \& Talk 26, 699 (2006).

[3] J.A. Bonito \& R.E. Sanders, Research on Language and Social Interaction 35, 481(2002).

[4] G. Ward \& J. Hirschberg, Language 61, 747 (1985).

[5] C. Goodwin, Discourse \& Society 18, 53 (2007).

[6] E. Goffman, Forms of Talk (University of Pennsylvania Press, Philadelphia, 2006).

[7] T.S. Kuhn, The Essential Tension (The University of Chicago Press, Chicago, 1977). instructional moves can make a big difference. The TA happened to overhear the students dismiss a good question, and rephrased the question in a way that encouraged students to discuss ideas they were not sure of.

The instructor's responsive encouragement of epistemic distance signaled to the students that it is okay to not know and to make sense of physics together. The tutorials themselves are open source [1], and can be adjusted to be phrased with more epistemic distancing. Even so, the responsiveness of the instructor proved critical in encouraging the students to discuss their ideas and to make sense of physics together.

\section{CONCLUSION}

In active engagement physics classrooms, students are given opportunities to share their ideas as they work collaboratively to understand phenomena. But to share ones' ideas about the phenomena involves risk of embarrassment and even conflict. Little is understood about how students and teachers alike manage this risk in creating a safe space to sensemake. I have shown a case study of how one group came to incorporate making sense of mechanisms into their discussions, finding that students' use of epistemic distancing played a key role. However, the use of epistemic distancing was not always productive - at first the group used too much to discuss their ideas. It took their instructor overhearing a good question, and rephrasing it with increasing amounts of epistemic distancing until the group was willing to share their ideas. It was his responsiveness and the students' subsequent use of epistemic distancing that allowed them to make space for sensemaking. This case highlights how epistemic distancing can be a powerful tool for students and instructors alike to mitigate the affective risk of disagreement in fostering productive scientific discussions in physics classrooms.

\section{ACKNOWLEDGEMENTS}

This work was funded by the National Science Foundation (Grant \#0440113). It builds on work by Rachel Scherr, who first noticed the phenomenon of tutorial students contributing ideas half-jokingly.

[8] R.E. Scherr and D. Hammer, Cogn. Instr. 27, 147 (2009).

[9] R.E. Scherr, Phys. Rev. ST PER 5, 020106 (2009)

[10] L.D. Conlin, Ph.D. Thesis, University of Maryland, College Park (2012).

[11] R. Russ, R.E. Scherr, D. Hammer, \& J. Mikeska, Science Education 92, 499 (2008).

[12] E.R. Sohr, B.W. Dreyfus, A. Gupta, \& A. Elby, PERC Proceedings (2015).

[13] Conlin \& Scherr (Under review). 